\title{
2.9 Upscaling Fluxes from Tower to Landscape: Overlaying Flux Footprints on High Resolution (IKONOS) Images of Vegetation Cover
}

\author{
J. Kim ${ }^{1,2}$, Q. Guo ${ }^{1}$, D. D. Baldocchi ${ }^{1}$, M. Y. Leclerc ${ }^{3}$, L. $\mathrm{Xu}^{1}$, and H. P. Schmid ${ }^{4}$ \\ ${ }^{1}$ ESPM/Ecosystem Science Division, University of California, Berkeley, CA 94720, USA \\ ${ }^{2}$ Department of Atmospheric Sciences, Yonsei University, Seoul 120-749, Korea \\ ${ }^{3}$ Laboratory for Environmental Physics, University of Georgia, Griffin, GA 30223-1797, USA \\ ${ }^{4}$ Department of Geography, Indiana University, Bloomington, IN 47405, USA
}

\section{INTRODUCTION}

We have evaluated the relevance of estimates of tower $\mathrm{CO}_{2}$ flux measurements in terms of spatial and temporal variability in source/sink strength distribution for three AmeriFlux sites. The temporal variability was accounted for by incorporating the effect of changing wind direction on tower flux footprints and by incorporating the diurnal cycles of stability dependent shrinking and expanding footprint domains into the vegetation density distribution, which was in turn related to the interpretation of net carbon exchange data (Horst an Weil, 1992, Schumid, 2002; Foken and Leclerc, 2004).

In this presentation, we describe the process of assessing tower footprint climatology, spatial variability of site vegetation density based on satellite image analysis, and the sensor location bias in scaling up to $1 \mathrm{~km} \times 1 \mathrm{~km}$ patch.

\section{METHODS AND MATERIALS}

Three flat sites with different vegetation cover and surface heterogeneity (Fig. 1) were selected from Ameriflux tower sites: the oak/grass site and the annual grassland site in a savannah ecosystem in northern California and a slash pine forest site in Florida, USA (Leclerc et al., 2003; Xu and Baldocchi, $2004 a, b)$. The site vegetation density was expressed in terms of normalized difference vegetation index (NDVI) and crown closure (CC) by analyzing the high resolution IKONOS satellite image (Fig. 1). At each site, the spatial structure of vegetation density was characterized using semivariogram and window size analyses (Levy et al., 2004). Footprint maps were produced by a simple model based on the analytical solution of the Eulerian advection-diffusion equation (Scumid, 1994, 1997). The resulting horizontal arrays of footprint functions were then superimposed with two flux indices: NDVI and CC. The latter is more variable in space and less variable in time whereas the former is variable in both space and time depending on site heterogeneity and environmental conditions (e.g., drought). We accounted spatial variability by integrating time-varying flux footprint maps to vegetation density maps (of NDVI and CC) obtained from high resolution IKONOS image analysis. The resulting footprint weighted NDVI and CC were then compared against the "true" average over the satellite domain of $1 \mathrm{~km}^{2}$ with the flux tower at the center.

\section{RESULTS}

Our results show the location biases $(\delta)$ for NDVI and CC to be less than $5 \%$ at the oak/grass and the slash pine forest sites. For the annual grassland site, $\delta$ is $28 \%$ for NDVI and $94 \%$ for CC. Considering the inherent uncertainties in tower flux measurements, the satellite image analysis with the limited dataset selected (1 image for the whole year), and the approximation of footprint climatology, a $\delta$ of $10 \%$ should be an acceptable criterion for testing our null hypothesis. We therefore conclude that there is no significant difference in flux indices (i.e., NDVI, CC) between those averaged for the satellite domain and those selected and weighted by the footprint criteria in the oak/grass site and the slash pine forest site. For the annual grassland site, however, scaling tower flux to $1 \mathrm{~km}^{2}$ patch would require cautions to take large $\delta$ into account. Temporal variability of the resulting location bias over the year was examined along with 16-day averages of MODIS-based NDVI and tower flux-based GPP. The results suggested that the validation data for carbon flux products derived from satellites and/or models with grid size of $\sim 1 \mathrm{~km}^{2}$ should be averaged at least for 4-8 days to properly incorporate the time and space scales involved in the measured processes.

The semivariogram and window size analyses are solely based on remote sensing data, which can be useful to provide important information in selecting tower location, or to pre-analyze the spatial heterogeneousness without detailed knowledge on meteorological data on the scene. A priori information 
on the degree of anisotropy is useful in flux footprint analysis in relation to the sensor location bias because of its strong dependence on site climatology of prevailing wind direction.
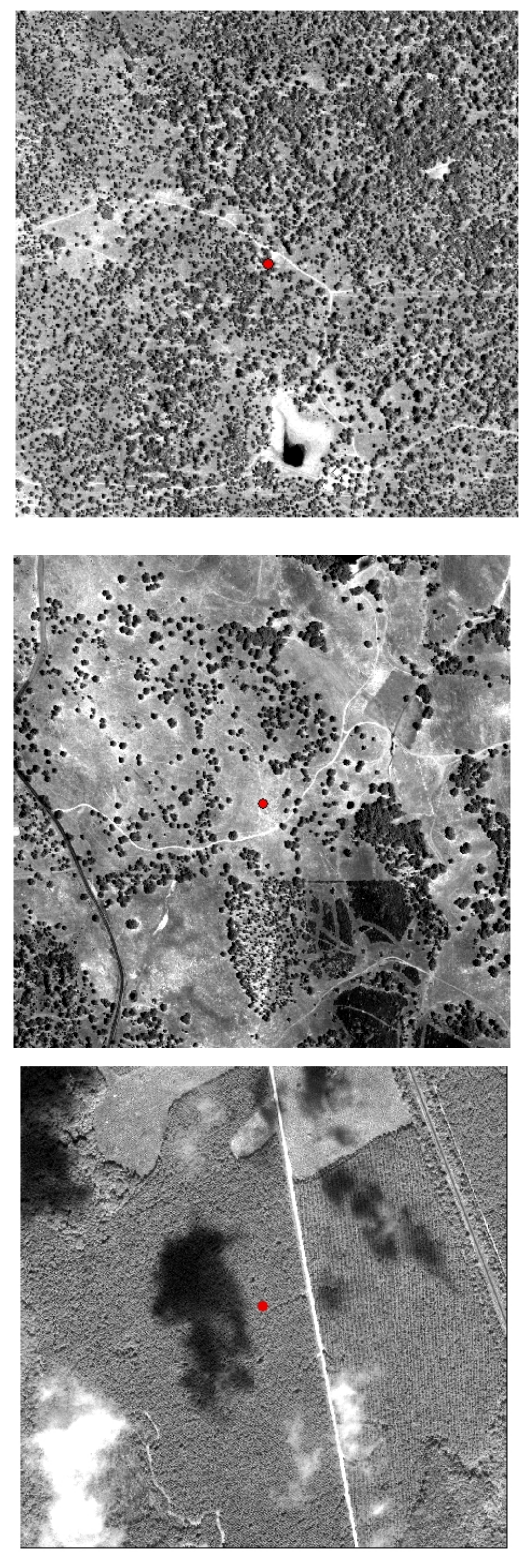

Figure 1 Images of the three sites, showing a $1 \mathrm{~km} \times 1$ $\mathrm{km}$ square around the flux tower (located at the center of each image), from the IKONOS panchromatic band, with $1 \mathrm{~m}$ spatial resolution: (a) oak/grass savannah, (b) grassland opening in savannah, and (c) slash pine forest plantation.

\section{Acknowledgment}

This study was funded by the US Department of Energy's Terrestrial Carbon Program, Grant No.
0006149 (Award register \# ER63024 0006149). Joon Kim is also supported partly by the Ministry of Environment of Korea through "The Eco-Technopia 21 Project" and The Ministry of Science and Technology (NRL Program).

\section{REFERENCES}

Foken and Leclerc, 2004. Methods and Limitations in Validation of Footprint Models. Special Issue : 'Footprints of Fluxes and Concentrations'. Agr. And Forest Meteorol. INVITED. (in press)

Horst, T. W. and Weil, J. C., 1992. Footprint estimation for scalar flux measurements in the atmospheric surface layer. Boundary-Layer Meteorol. 59, 279-318.

Leclerc, M. Y., Karipot, A., Prabha, T., Allwine, G., Lamb B., Gholz, H. L., 2003. Impact of non-local advection on flux footprints over a tall forest canopy: a tracer flux experiment. Agric. For. Meteorol. 115, 19-30.

Levy, P. E., Baldocchi, D. D., Grelle, A., Miller, S., Milne, R., Wofsy, S. C., 2004. Effects of spatial heterogeneity on sampling errors in $\mathrm{CO} 2$ flux measurements over uneven-aged forests. Agric. For. Meteorol. (submitted).

Schmid, H. P., 1994. Source areas for scalars and scalar fluxes. Boundary-Layer Meteorol. 67, 293-318.

1997. Experimental design for flux measurements: Matching scales of observations and fluxes. Agric. For. Meteorol. 87, 179-200.

2002. Footprint modeling for vegetation atmosphere exchange studies: a review and perspective. Agric. For. Meteorol. 113, 159-183.

Xu, L. and Baldocchi, D. D., 2003a. Seasonal trend of photosynthetic parameters and stomatal conductance of blue oak (Quercus douglasii) under prolonged summer drought and high temperature, Tree Physiology, (in press)

and Baldocchi, D. D., 2003b. Seasonal variation in carbon dioxide exchange over a Mediterranean annual grassland in California. Agric. For. Meteorol. (in press). 